\title{
Polylactide/Biopolyethylene Bioblends
}

\author{
Gustavo F. Brito, Pankaj Agrawal, Edcleide M. Araújo, Tomás J. A. de Mélo \\ Department of Materials Engineering, Federal University of Campina Grande
}

\begin{abstract}
In this work, Polylactide/Biopolyethylene blends were developed. Although some studies have been carried out on polylactide/polyethylene blends, none of them has used polyethylene synthesized with raw material obtained from natural sources. Due to the incompatibility between polylactide and polyethylene, E-GMA and EMA-GMA compatibilizers were used. These compatibilizers present glycidyl methacrylate groups in their structure, which may react with the functional end-groups of polylactide. To evaluate the properties, the blends were characterized by mechanical tests, scanning electron microscopy (SEM) and melt flow index (MFI). The results indicated that the compatibilizers played an important role in the blends, interacting with the blends components, modifying the morphology and improving the mechanical properties.
\end{abstract}

Keywords: Polylactide, biopolyethylene, biopolymers, bioblends, biodegradable polymers.

\section{Introduction}

The Polylactide or Poly(Lactic Acid) (PLA) is one of the most promising biopolymers for various applications owing to its competitive cost, biocompatibility, biodegradability, low environmental impact, excellent transparency, good processability and good mechanical properties and thermal stability. However, PLA inherent brittleness is a major drawback that prevents its use in a wide range of applications. To overcome this problem, melt blending PLA with other polymers has proved to be the most economic and practical route ${ }^{[1-4]}$.

Since 2010, Braskem, a Brazilian petrochemical company, has been commercializing the green polyethylene (Biopolyethylene). The adjective green is used to indicate that the ethylene used as raw material to synthesize the green polyethylene is derived from sugarcane. According to Braskem, for each ton of green polyethylene produced, 2.5 tons of $\mathrm{CO}_{2}$ are captured from the atmosphere and remains sequestered for the plastic's entire life cycle. During its combustion the $\mathrm{CO}_{2}$ released to the atmosphere will be captured again by the sugarcane in the next harvest, thereby mantaining the balance of $\mathrm{CO}_{2}$ in the nature. Apart from being an eco-friendly material, Bio-PE presents the same technical properties and processability of the resin made from fossil sources. Thus, processing the green plastic does not require any new investments in equipment or technical adjustments ${ }^{[5-7]}$.

Some works ${ }^{[3,8-13]}$ have been blending PLA with PE. However, to date, there are no studies in the literature that uses a PE synthesized with raw material obtained from renewable sources, and ethylene/methyl acrylate/glycidyl methacrylate terpolymer (EMA-GMA) as compatibilizer to this kind of blends.

The term bioblends is used by some authors to refer to polymer blends in which at least one of the components is a biodegradable polymer ${ }^{[14,15]}$. Other authors, however, use this term to refer to polymer blends in which at least one of the components is a biopolymer ${ }^{[16]}$. However, the first definition is more common. So Polylactide/Biopolyethylene may be consider a bioblend, since both of the blend components are biopolymers and, in addition, the polylactide is a biodegradable polymer ${ }^{[5]}$.

The aim of this study is to improve the mechanical properties of PLA by melt blending it with Biopolyethylene, forming a bioblend, in order to expand its applications. However, this blend is incompatible and thus the addition of a compatibilizer is required to promote a synergism among the properties of PLA and PE.

\section{Experimental}

\section{Materials and sample preparations}

Polylactide (PLA) NatureWorks ${ }^{\mathrm{TM}}$ 2002D, MFI = 4-8 g/10 min, $\mathrm{E}=3.5 \mathrm{GPa}$, supplied by Cargill. The compatibilizers Lotader ${ }^{\mathrm{TM}}$ AX8900, an ethylene/methyl acrylate/glycidyl methacrylate terpolymer (EMA-GMA), MFI $=6 \mathrm{~g} / 10 \mathrm{~min}, \mathrm{E}=8 \mathrm{GPa}$ and Lotader $^{\mathrm{TM}}$ AX8840, an ethylene/glycidyl methacrylate copolymer (E-GMA), MFI = 5 g/10 min, E = 104 GPa, supplied by Arkema. Linear low-density polyethylene (LLDPE) I'm Green ${ }^{\mathrm{TM}}$ SLH218, MFI = $2.3 \mathrm{~g} / 10 \mathrm{~min}$, supplied by Braskem.

Prior to extrusion, PLA pellets were vacuum-dried at $80{ }^{\circ} \mathrm{C}$ for 4 hours. Melt blending was performed using a co-rotating twin-screw extruder (Werner-Pfleiderer ZSK-18 with $\mathrm{L} / \mathrm{D}=40$ ) at $180{ }^{\circ} \mathrm{C}$ and a screw rotation speed of $250 \mathrm{rpm}$. For all blends, the weight ratio of PLA/PE was 80/20. In the compatibilized blends, the amount of compatibilizer used was 5 parts per hundred of resin (phr). After being dried under vacuum at $80{ }^{\circ} \mathrm{C}$ for 12 hours, the extruded pellets were injection-molded, using a Fluidmec H3040, into ASTM standard specimens at a melt temperature of $170{ }^{\circ} \mathrm{C}$ and at a mold temperature of $20^{\circ} \mathrm{C}$.

\section{Characterizations}

Tensile tests were conducted in a universal testing machine (Shimadzu AG-IS) at a crosshead speed of $50 \mathrm{~mm} / \mathrm{min}$ following ASTM D638. Notched Izod impact tests were performed according to ASTM D256 using a Resil 5.5 Pendulum Impact tester (Ceast). Average test values from five replicated specimens were taken for each sample.

Scanning electron microscopy (SEM) analyses were carried out on the fracture surfaces of the impact samples using a Shimadzu SSX-550 Superscan scanning electron microscope at an accelerating voltage of $15 \mathrm{kV}$. The fracture surfaces were sputter-coated with gold prior to the analysis.

The melt flow index (MFI) of the extruded pellets was determined using a melt flow instrument PIN 7026 (CEAST). The melt index was measured at $190{ }^{\circ} \mathrm{C}$ with a weight of $2.16 \mathrm{~kg}$ according to ASTM D1238. The pellets were dried under vacuum at $80{ }^{\circ} \mathrm{C}$ for 12 hours before the MFI tests. 


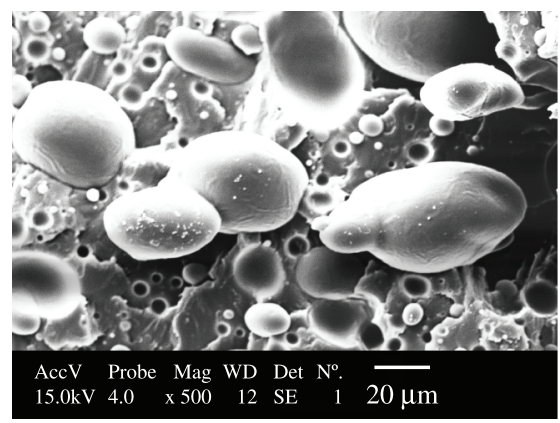

(a)

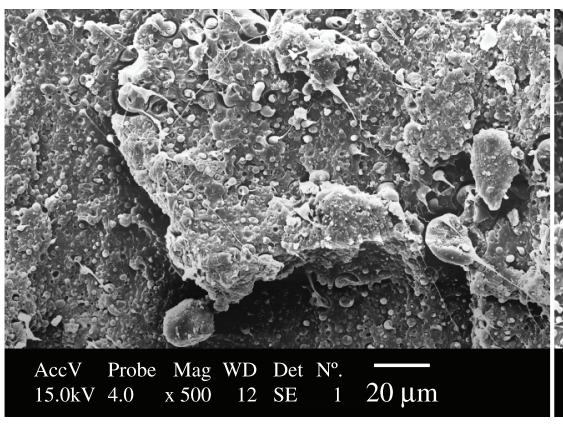

(b)

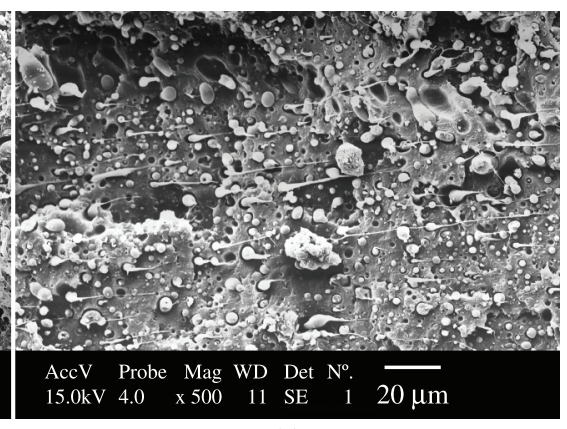

(c)

Figure 1. SEM micrographs of the blends (a) PLA/PE (80/20), (b) PLA/PE/E-GMA (80/20/5) and (c) PLA/PE/EMA-GMA (80/20/5). 500×.

\section{Results and Discussion}

Morphology. Since mechanical properties of multiphase polymer blends depend largely on the resulting morphologies, SEM analysis was employed to identify the phase structure of the blends. Figure 1 shows the SEM micrographs of fracture surface micrographs of PLA/PE binary blends and PLA/PE/E-GMA and PLA/PE/EMA-GMA ternary blends. The binary blend shows large PE dispersed phase domains as well as PE particles that were pulled out from the PLA matrix indicating poor interfacial adhesions (Figure 1a). The ternary blends show a finer PE dispersed phase and better wetting of dispersed phase by the matrix than the binary blends (Figure 1b, c). On the basis of the micrographs it can be inferred that the presence of the compatibilizers in the ternary blends leads to a finer PE dispersed phase and improves the adhesion between PLA and PE due to reactions between PLA functional end-groups and the GMA groups present in both compatibilizers ${ }^{[13,17]}$. These reactions may be favored by molecular weight reduction that occurs during processing, thereby increasing the number of PLA end-groups ${ }^{[18,19]}$. The compatibilizers also have affinity with the polyethylene due to the presence of ethylene blocks in their structures.

Mechanical properties. Figure 2 shows the values of modulus and impact strength of PLA, PLA/PE binary blend and PLA/PE/ compatibilizer ternary blends. The impact strength of the PLA/PE binary blends exhibited a small loss when compared to that of neat PLA. This result is in agreement with the micrograph presented in Figure 1a, which shows large PE particles into PLA matrix and poor adhesion between PLA and PE phases, resulting in the decrease of the property. On the other hand, the ternary blends displayed remarkable improvement in impact strength which was more pronounced for the blends with EMA-GMA than that for the blend with E-GMA. This may be attributed to the presence of MA groups in EMA-GMA which make it more flexible than the E-GMA. Unlike the impact strength, the tensile modulus of the blends was lower than that of neat PLA. Kim et al. ${ }^{[13]}$, studying PLA/PE/E-GMA blends, obtained good improvement on the strain at break, about $78 \%$. However, the impact strength and the modulus were not reported by the authors.

Melt flow index. The melt flow index values of neat PLA, PLA/PE and PLA/PE/compatibilizer blends are given in Table 1. PLA/PE binary blend presents a melt index value between the values of PLA and PE neat polymers, whereas, the ternary blends present a significant decrease in the melt fluidity (from 3.0 to 1.4 for the PLA/PE/E-GMA blend and from 3.0 to 0.5 for PLA/PE/E-GMA blend). These results indicate the formation of PLA-E-GMA and PLA-EMA-GMA copolymers during the extrusion process, probably due the formation of bonds between the epoxy groups present in GMA and the carboxyl and hydroxyl functional end-groups present in PLA, as suggested by the authors in previous work ${ }^{[17]}$, based on FTIR characterizations, and also by other authors ${ }^{[2,4,20]}$.

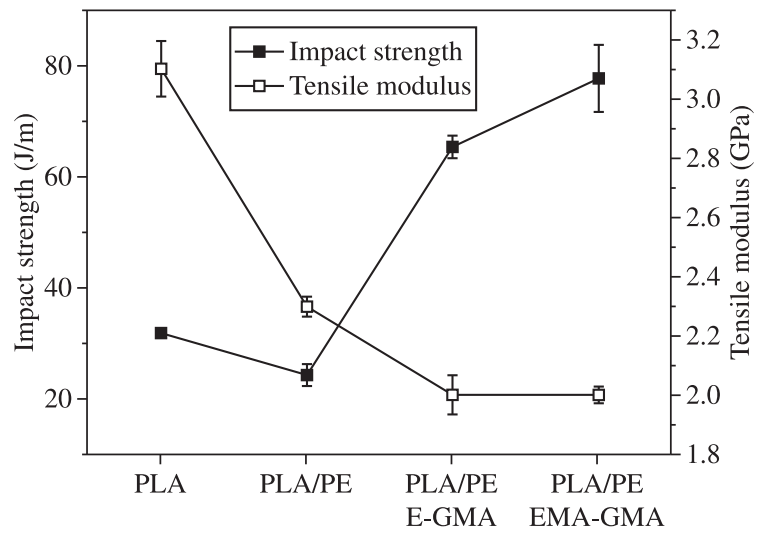

Figure 2. Mechanical properties of neat PLA and blends PLA/PE, PLA/PE/E-GMA and PLA/PE/EMA-GMA.

Table 1. Melt index of neat PLA and blends.

\begin{tabular}{cc}
\hline Materials & MFI (g/10 min) \\
\hline PLA & 4.5 \\
PE & $2.3^{*}$ \\
E-GMA & $5.0^{*}$ \\
EMA-GMA & $6.0^{*}$ \\
PLA/PE & 3.0 \\
PLA/PE/E-GMA & 1.4 \\
PLA/PE/EMA-GMA & 0.5 \\
\hline
\end{tabular}

*provided by the manufacturer

\section{Conclusion}

Bioblends of PLA/Biopolyethylene were developed with the aim of making the PLA less rigid and brittle. To make the PLA/PE bioblend compatible, E-GMA and EMA-GMA were used as compatibilizers. SEM micrographs analisys evidenced that a finer PE dispersed phase and a better wetting of PE by the PLA matrix were obtained for the ternary blends. The results of mechanical tests revealed that the ternary blends presented a remarkable improvement in the impact strength which was more pronounced for the blends with the EMA-GMA terpolymer. The melt flow index of the ternary blends presented a significant decrease when compared to that of neat PLA and the binary blends, which indicates the formation of PLA-E-GMA and PLA-EMA-GMA copolymers.

\section{Acknowledgements}

The authors would like to gratefully acknowledge for the financial support from $\mathrm{CNPq}$ and CAPES, and also to thank the companies Arkema, Braskem and Cargill for kindly providing the materials for this work. 


\section{References}

1. Barcellos, I. O.; Andreaus, J.; Battisti, A. M. \& Borges, J. K. - Polímeros, 18, p.256 (2008).

2. Liu, H.; Chen, F.; Liu, B.; Estep, G. \& Zhang, J. - Macromolecules, 43, p.6058 (2010). http://dx.doi.org/10.1021/ma101108g

3. Balakrishnan, H.; Hassan, A.; Wahit, M. U.; Yussuf, A. A. \& Razak, S. B. A. - Mater. Design, 31, p.3289 (2010). http://dx.doi.org/10.1016/j. matdes.2010.02.008

4. Liu, H.; Song, W.; Chen, F.; Guo, L. \& Zhang, J. - Macromolecules, 44, p.1513 (2011). http://dx.doi.org/10.1021/ma1026934

5. Brito, G. F.; Agrawal, P.; Araújo, E. M. \& Mélo, T. J. A. - Rev. Eletr. Mater. Proc., 6, p.127 (2011).

6. Polímeros, 19, (2009). Disponível em: <http://bit.ly/xc8bEf>. Acesso em: 21 dez. 2011.

7. Braskem. Disponível em: <www.braskem.com>.

8. Wang, Y. \& Hillmyer, M. A. - J. Polym. Sci., Part A: Polym. Chem., 39, p.2755 (2001). http://dx.doi.org/10.1002/pola.1254

9. Anderson, K. S.; Lim, S. H. \& Hillmyer, M. A. - J. Appl. Polym. Sci., 89, p.3757 (2003). http://dx.doi.org/10.1002/app.12462

10. Anderson, K. S. \& Hillmyer, M. A. - Polymer, 45, p.8809 (2004). http://dx.doi.org/10.1016/j.polymer.2004.10.047

11. Omura, M.; Tsukegi, T.; Shirai, Y.; Nishida, H. \& Endo, T. - Ind. Eng. Chem. Res., 45, p.2949 (2006). http://dx.doi.org/10.1021/ie051446x

12. Singh, G.; Bhunia, H.; Rajor, A. \& Choudhary, V. - Polym. Bull., 66, p.939 (2011). http://dx.doi.org/10.1007/s00289-010-0367-x
13. Kim, Y. F.; Choi, C. N.; Kim, Y. D.; Lee, K. Y. \& Lee, M. S. - Fiber Polym., 5, p.270 (2004). http://dx.doi.org/10.1007/BF02875524

14. Mohamed, A.; Gordon, S. H. \& Biresaw, G. - Polym. Degrad. $\begin{array}{lllll}\text { Stabil., } & 92, & \text { p.1177 } & \text { (2007). } & \text { http://dx.doi.org/10.1016/j. }\end{array}$ polymdegradstab.2007.04.012

15. Mohamed, A.; Finkenstadt, V. L.; Gordon, S. H. \& Palmquist, D. E. - J. Appl. Polym. Sci., 118, p.2778 (2010). http://dx.doi.org/10.1002/ app. 32260

16. Haq, M.; Burgueño, R.; Mohanty, A. K. \& Misra, M. - Compos. Sci. Technol., 68, p.3344 (2008). http://dx.doi.org/10.1016/j. compscitech.2008.09.007

17. Brito, G. F.; Agrawal, P.; Araújo, E. M. \& Mélo, T. J. A. - Polímeros, 22, p.164 (2012). http://dx.doi.org/10.1590/S0104-14282012005000025

18. Carrasco, F.; Pagès, P.; Gámez-Pérez, J.; Santana, O. O. \& Maspoch, M. L. - Polym. Degrad. Stabil., 95, p.2508 (2010). http://dx.doi. org/10.1016/j.polymdegradstab.2010.07.039

19. Nishida, H. - "Thermal Degradation", in: Poly(Lactic Acid), cap.23, Auras, R.; Lim, L. T.; Selke, S. E. M. \& Tsuji, H. (eds.), John Wiley \& Sons, Inc., New Jersey (2010). http://dx.doi. org/10.1002/9780470649848.ch23

20. Li, Y. \& Shimizu, H. - Eur. Polym. J., 45, p.738 (2009). http://dx.doi. org/10.1016/j.eurpolymj.2008.12.010

Enviado: 27/12/11

Reenviado: 15/02/12

Aceito: 14/04/12 